\title{
Does size matter? An assessment of quota market evolution and performance in the Great Barrier Reef fin-fish fishery
}

\author{
James Innes $^{1}$, Olivier Thébaud ${ }^{1,2,3}$, Ana Norman-López ${ }^{1}$ and L. Richard Little ${ }^{1}$
}

\begin{abstract}
In fisheries managed using individual transferable quotas (ITQs) it is generally assumed that quota markets are wellfunctioning, allowing quota to flow on either a temporary or permanent basis to those able to make best use of it. However, despite an increasing number of fisheries being managed under ITQs, empirical assessments of the quota markets that have actually evolved in these fisheries remain scarce. The Queensland Coral Reef Fin-Fish Fishery (CRFFF) on the Great Barrier Reef has been managed under a system of ITQs since 2004. Data on individual quota holdings and trades for the period 2004-2012 were used to assess the CRFFF quota market and its evolution through time. Network analysis was applied to assess market structure and the nature of leasetrading relationships. An assessment of market participants' abilities to balance their quota accounts, i.e., gap analysis, provided insights into market functionality and how this may have changed in the period observed. Trends in ownership and trade were determined, and market participants were identified as belonging to one out of a set of seven generalized types. The emergence of groups such as investors and lease-dependent fishers is clear. In 2011-2012, 41\% of coral trout quota was owned by participants that did not fish it, and $64 \%$ of total coral trout landings were made by fishers that owned only $10 \%$ of the quota. Quota brokers emerged whose influence on the market varied with the bioeconomic conditions of the fishery. Throughout the study period some quota was found to remain inactive, implying potential market inefficiencies. Contribution to this inactivity appeared asymmetrical, with most residing in the hands of smaller quota holders. The importance of transaction costs in the operation of the quota market and the inequalities that may result are discussed in light of these findings.
\end{abstract}

Key Words: catch shares; Great Barrier Reef; line fishery; market efficiency; social network analysis; transaction costs

\section{INTRODUCTION}

Individual transferable quotas (ITQs) are increasingly being used as a means of managing commercial fisheries, with as much as $28 \%$ of annual global catch coming from fisheries regulated by ITQs in recent years (Chu 2009, Arnason 2012). As a management tool, ITQs have a number of potentially attractive features, central to which is the theoretical ability to reduce the inefficiencies typically associated with derby fisheries and to increase resource rents in the process (Moloney and Pearse 1979, Clark 1980, Squires et al. 1995, Grafton 1996, Grafton et al. 2000). This ability rests on the assumption that setting an appropriate total allowable catch (TAC) and allocating defined shares of the catch to individual operators will replace wasteful incentives to race and overcapitalize, with incentives to reduce costs, increase value, and act in a less myopic manner. If there is heterogeneity within the fleet, the ability to transfer quota between operators can further increase efficiency gains by creating the incentive for less efficient operators to sell out or lease their quota to those who are more efficient and for whom the quota has a higher marginal value (Arnason 1993, Herrmann 1996, Knapp 1997, Grafton et al. 2000, Hartley and Fina 2001, Grimm et al. 2012).

In principle, and within a well-functioning market, it is suggested that the propensity for quota to be reallocated to more efficient operators should result in a socially optimal distribution of quota, irrespective of how, and to whom, it was initially allocated (Montgomery 1972, Moloney and Pearse 1979, Arnason 1990). However, factors such as poor participation and insufficient trades (thin markets) resulting in high transaction costs and illiquidity, limited information, or the existence of participants with excessive market power can result in market failure (Farrell
1987, Stavins 1995). Long-run efficiency gains are then reduced and an efficient distribution of quota is not ultimately achieved (Anderson 1991, 2008). The structure and dynamics of quota markets thus play an important role in determining the ultimate effectiveness of ITQs as a management tool. However, it has also been argued that in a fisheries context the most efficient mechanism of initially allocating quota may be through a process referred to as grandfathering (Anderson et al. 2011), whereby quota is given to existing participants under the assumption that their experience and skill makes them best placed to use it. It has certainly been the most commonly applied approach when establishing ITQ management systems, but does rely in part on the assumption that there will be little need for subsequent reallocation. If, for example, significant numbers of those awarded quota retire and start leasing their quota out, it may result in ownership legacies, which endure in the resulting markets.

Empirical studies of fishing quota markets, their efficiency, and their evolution over time are still relatively few (Thébaud et al. 2012). Studies that focus on the factors that may limit efficiency of real life quota markets are even fewer. The unpredictable nature of prices, costs, and catching conditions were cited as having contributed to a situation of highly imperfect information, and consequently, volatility in quota prices in the early days of New Zealand's quota management system (Lindner et al. 1992). More recent work indicates this is no longer an issue in New Zealand (Newell et al. 2005). The implications of intentionally imposing constraints on the way in which a market can operate, such as limits to the quantity of quota that may be traded or owned or who it might be traded with, are better studied and empirically

${ }^{1}$ CSIRO Oceans and Atmospheres Flagship, ${ }^{2}$ Ifremer, UMR M101, AMURE, Unité d'Économie Maritime, ${ }^{3}$ Adjunct Professor with the School of Economics and Finance, Queensland University of Technology 
demonstrate the possible foregone efficiency gains of such restrictions from an economic perspective (Kroetz and Sanchirico 2010). Although the ability to achieve stated management objectives ultimately defines what may be considered successful or efficient management, understanding the potential tradeoffs involved with particular decisions ex-ante is useful information for managers.

We examined the market for ITQs in the Queensland coral reef fin-fish fishery (CRFFF) on the Great Barrier Reef. Using data on individual quota holdings, trades, and catch, we characterized the evolution of the CRFFF quota market, focusing on lease trades for coral trout quota. Coral trout is a key species in the fishery and the most significant component in terms of quantity landed and gross value of production (GVP). The results provide empirically grounded insights into how ITQ markets can evolve over time and whether, in this instance, they have performed as may have been expected from a theoretical perspective, and as would be required for the potential benefits of ITQ management to be realized. In particular, we found that, throughout the study period some quota remained inactive, implying potential market inefficiencies. Contribution to this inactivity appeared asymmetrical, with most residing in the hands of smaller quota holders. The importance of transaction costs in the operation of the quota market and the inequalities that may result are discussed in light of these findings

\section{The coral reef fin-fish fishery}

Queensland's CRFFF targets primarily demersal reef-associated fish and operates from the middle to the far north of Australia's east coast (Fig. 1). A significant proportion of this area, the Great Barrier Reef Marine Park (GBRMP), is managed by the Great Barrier Reef Marine Park Authority (GBRMPA). The fishery is highly diverse in nature and consists of the commercial reef quota (RQ) fishery, a charter sector, and in some parts of its range, a substantial recreational component. It is multispecies in nature and the key commercial species groups include coral trout, red throat emperor, and a range of other cods, groupers, sweetlips, tropical snappers, seaperches, and emperors (DEEDI 2011).

The market for landings can be divided into two main components, one that is export oriented and one that is domestic. The domestic market primarily consumes dead fish (both fresh and frozen), whereas the export market is predominantly for live coral trout, which are sent to Hong Kong. Live fish accounted for $87 \%$ of all coral trout landings in 2010-2011. Gross values of commercial landings, estimated at ex-vessel prices, for coral trout, red throat emperor, and other species were respectively $\mathrm{A} \$ 38$ million (A \$36 million live, \$A2 million dead), \$A2 million, and \$A3 million in the 2010-2011 financial year, illustrating coral trout's significance in terms of value.

The commercial sector is managed under the Queensland legislation: Fisheries Act 1994, Fisheries Regulation 2008, and the Fisheries (Coral Reef Fin Fish) Management Plan 2003. A suite of input and output controls apply, which includes limited entry (via a licensing system), maximum size limits for vessels, gear restrictions, minimum and maximum landing sizes, and total allowable catches (TACs). Other than two five-day spawning closures, one in October and one in November, the fishery operates year round, with seasonal variation caused by market and weather-related factors. Reef quota vessels are also subject to spatial restrictions on where they can operate as part of the GBRMP and Queensland Marine Parks Zoning Plans (GBRMPA 2004).

Fig. 1. Map illustrating the coral reef fin-fish fishery (CRFFF) range on Australia's east coast and the Great Barrier Reef.

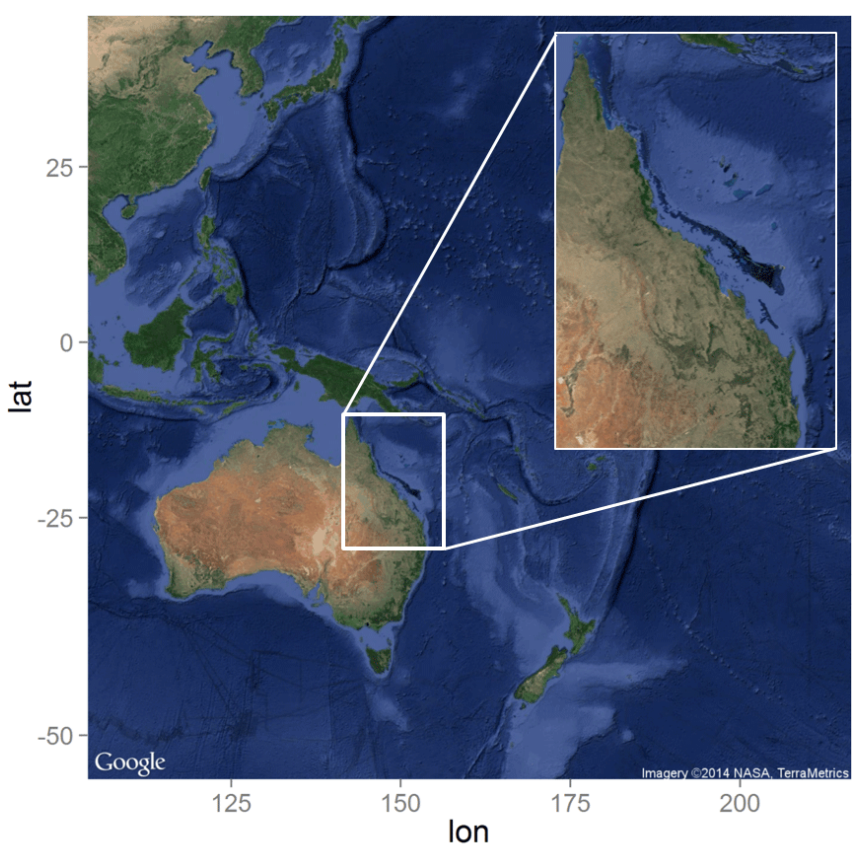

Total allowable catches were adopted by the commercial sector on July 1, 2004, at which time commercial license holders were allocated individual tradable quotas (ITQs) based primarily on the historical catch records associated with their license, i.e., grandfathering. There are three types of RQ quota: coral trout (CT), red throat emperor (RTE; Lethrinus miniatus), and other species (OS). As the name suggests OS incorporates a number, approximately 154 , of other reef fish species, but the commercial fishery only actively targets a relatively small proportion of these. Coral trout quota covers seven separate species of coral trout but the majority of landings consist of the common coral trout (Plectropomus leopardus). When first allocated, all fishery participants who qualified for an RQ license also received a minimum quota allocation of $800 \mathrm{CT}$ units, 400 RTE units, and 800 OS units. Under current conditions, one quota unit represents one kilogram of fish, live weight equivalent, for all quota types. However there is some capacity for this to be adjusted if specified catch triggers are reached (DPI 2003). All quota is fully tradable, in both permanent and temporary, i.e., leased, trades. Leased quota automatically reverts back to the owner at the end of each year.

The TACs were introduced along with the implementation of the GBRMPA Representative Areas Program. The latter increased the area of no-take zones in the GBRMP from $<5 \%$ to $>33 \%$ and was accompanied by a statewide fisheries buyback program. Following this, the available TACs for CT, RTE, and OS were set at 1214 tonnes, 615 tonnes, and 902 tonnes, respectively (see Appendix 1 for further information on the TAC). Reef quota 
Fig. 2. Landings over time for coral trout, other species, and red throat emperor quota groups. Total allowable catches (beginning 2004-2005) are denoted by the dashed horizontal lines.

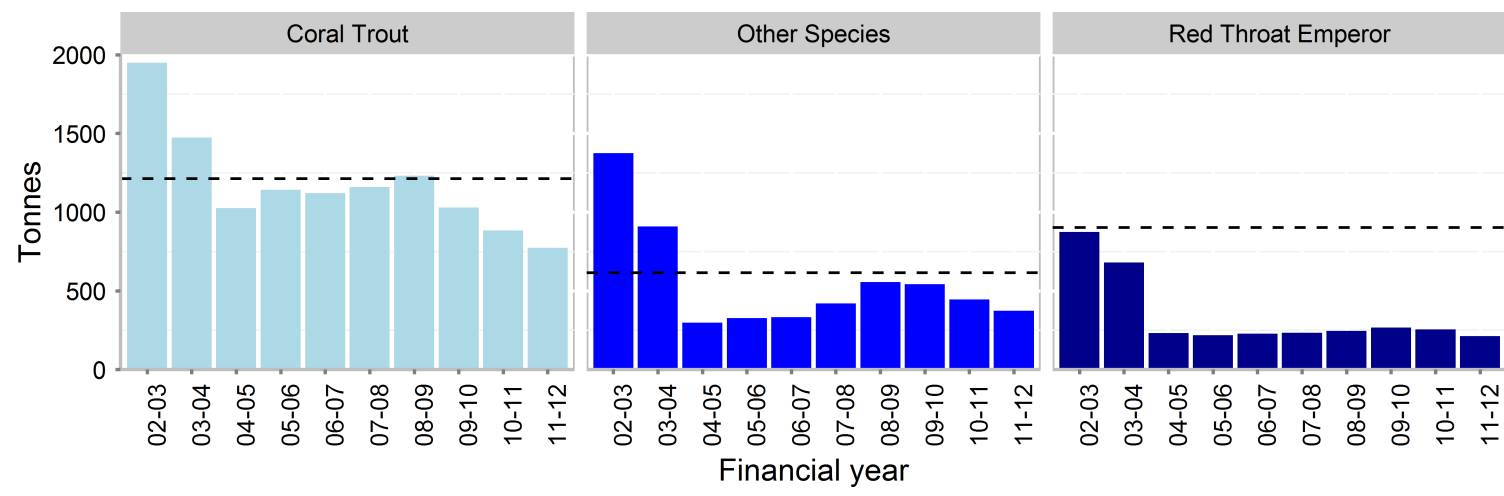

effort and landings fell sharply in 2004-2005 and have since remained low compared to the prequota era. To date, only landings of CT have managed to reach their TAC and only in 2008-2009, so TACs cannot currently be considered to actively constrain the RQ fishery's overall level of output (Fig. 2). In more recent years, two significant cyclone events, Hamish in March 2009 and Yasi in February 2010, have also contributed to a decline in effort, landings, and catch per unit of effort (cpue) across the whole fishery.

In what follows, we focus on the CT component of the RQ quota market because this has contributed most to the GVP of the fishery and has been the component for which access to quota was most constraining over the period considered. The analysis presented is centered on short-term lease trades for CT catch shares, which represented the most active component of this market.

\section{DATA AND METHODS}

\section{Data}

The Queensland Department of Agriculture Fisheries and Forestry (QDAFF) records all quota transactions, along with the quantity of quota held and fished by each separate quota account. The analysis we present is based on an anonymous version of this data. The dataset covers the period since ITQs were first introduced on July 1, 2004, up to the end of the 2011-2012 financial year, i.e., June 30 in Australia. As is common in many fisheries managed under ITQs, there is no requirement to report the dollar value of quota transactions along with the quantity traded, meaning that quota trade prices, and how these have evolved over time, are not directly available. Anecdotal price information collected as part of an economic survey of the RQ fishery indicated that CT quota prices have generally declined over time (Thébaud et al. 2014).

Descriptive analysis of coral trout (CT) quota market dynamics Standard descriptors were used to characterize trends in the CT quota market. This included measures of the number of quota accounts and the proportion of these actively engaged in trading, the number of permanent and temporary trades, the volume of these trades compared to landings, as well as concentration of quota ownership using the Gini index (Gini 1921).
Analyzing the quota market as a network

Markets can be considered as social networks, the properties of which bear direct relation with the ability of information to spread between operators, and may have important implications for overall market efficiency. In a fisheries context, the significance of social networks has been established with respect to compliance (Hatcher et al. 2000), viability during resource scarcity (RamirezSanchez and Pinkerton 2009), relationships between fish traders (Weisbuch et al. 2000), and collaborative management (BarnesMauthe et al. 2013). To the best of our knowledge, a study of the Tasmanian rock lobster (Panulirus cygnus) ITQ market (van Putten et al. 2011) is the only previous example of social network analysis being used to assess quota markets in the context of fisheries.

Social network analysis (Scott 1991, Wasserman and Faust 1994, Haythornthwaite 1996) is the mapping and quantification of relationships between individual entities. Based upon the principals of network theory (Strogatz 2001, Barabási 2005), network maps and statistical measures are used to illustrate and mathematically assess a network's properties and indicate how these may have changed over time. The structure of networks, the associated descriptive statistics, and how these change over time indicate how information is likely to pass through networks, the ability of one entity to interact with another, and the relative degree of control each entity may exert over exchanges in the network. Early work in the area assumed the structural distribution of network connections was random (Erdős and Rényi 1959) but more recently it has been shown that real life networks, especially those in the social/economic domains often display markedly nonrandom, so called 'scale-free,' properties (Barabási and Albert 1999, Barabási 2009).

In the context of the CRFFF, we used these analytical methods to formally identify the existence and nature of trading relationships between anonymous account holders in the market for RQ quota. Using the NetworkAnalyser component of the open source platform Cytoscape (Assenov et al. 2008), we computed standard network descriptors to characterize the structure of the CT quota lease market and how this has changed over time (see Appendix 1 for detailed definitions of the descriptors calculated). 


\section{Individual strategies in a quota market}

Individual operators may become involved in a quota market in different ways, leading them to take different roles in the market. Using typologies similar to those of van Putten and Gardner (2010), we characterized the individual CT quota holders based on their observed trading and fishing behaviors (Table 1). In a particular year, some operators may keep actively fishing and seek to lease quota in to complement their initial allocation (lease dependent), or lease quota out to gain additional income (income supplementer). Other operators, either ex-fishers or nonfishers, may derive income exclusively from leasing out the quota they own (investor). However, other operators may take on a brokerage role, leasing quota in and out, while also being actively fishing (quota redistributor). As some of these will be more specialized in their roles as brokers, quota redistributors were split into those who landed one tonne of fish or more and those who landed less. There may be operators who decided to stay outside the quota market and only fish the quota they own (independent). Finally, there are operators, who neither leased nor fished the quota they own, remaining inactive over a period of time (inactive). The diversity of individual strategies observed in real markets may at least partially be driven by the structure of the market and be influenced by factors such as imperfect information or the transaction costs associated with quota trading, which may not be the same for all participants.

Table 1. Account holder typology definitions.

\begin{tabular}{lccc}
\hline \hline Typology & CT catch & Lease in & Lease out \\
\hline Income supplementer & $>0$ & 0 & $>0$ \\
Independent & $>0$ & 0 & 0 \\
Investor & 0 & 0 & $>0$ \\
Lease dependent & $>0$ & $>0$ & 0 \\
Quota redistributor $<1 \mathrm{t}$ & $<1 \mathrm{t}$ & $>0$ & $>0$ \\
Quota redistributor $\geq 1 \mathrm{t}$ & $\geq 1 \mathrm{t}$ & $>0$ & $>0$ \\
Inactive $^{\dagger}$ & 0 & $\geq 0$ & 0 \\
\hline
\end{tabular}

In practice this category includes the few cases in which account holders leased in quota but then did nothing with it. This also means that there are instances in which accounts hold zero quota at the beginning of the year.

\section{Measuring market functionality}

Many of the expected benefits of implementing ITQ management are intrinsically dependent on a well-functioning quota market. In the absence of time series data for quota prices, we used data on the quantity of quota held and traded by individual operators to assess the extent to which the CT quota market could be considered efficient. In a well established and functioning market, quota holders would typically aim, and be able, to balance their account at the annual level, so that not only do they hold enough quota to cover their catches, but by the end of each financial year, any excess quota has also been leased out. This is because unused quota units entail both cash costs in terms of annual management fees (set by QDAFF at A \$0.33 per unit owned; Fisheries Act 1994, Fisheries Regulation 2008) and the opportunity costs of foregone lease income or profits, if these are positive. Unlike a number of other ITQ managed fisheries, e.g., Iceland, New Zealand, the
CRFFF has no provision for account holders to carry over any proportion of unused quota into the next financial year, so that these costs cannot be compensated for by increased revenues in the future.

Following Connor and Alden (2001), we derived a 'gap' measure, defined as the difference between quota held and quota used for each anonymous account holder at the end of the financial year, and used this to assess the extent to which operators on the CT quota market have been able to operate efficiently (see Appendix 1 for detailed explanation). The presence of factors, such as poor information, high transaction costs and illiquidity, and insufficient demand, can be expected to impair the ability of account holders to balance their accounts at the annual level, leading to positive gap values. We also considered variability in this gap between different operator types on the quota market. A detailed explanation relating to how the measures were calculated is provided in Appendix 1.

When demand for quota exists, a priori expectations are that gaps are likely to be most common and larger in the early stages of an ITQ system as quota holders learn, develop trading connections, and adapt to the new management regime. The ability of account holders to balance their accounts is expected to improve relatively rapidly as the market develops and links with other account holders are established, so that over time the average gap size will decrease as the system develops and matures. It is also assumed that bigger players in the fishery, i.e., those that hold a relatively large proportion of the TAC, will initially have a natural advantage with respect to access to information and the relative size of any search and transaction costs. This asymmetry is expected to result in a negative correlation between the amount of quota they hold and the size of their gap at the end of the financial year, and the strength of this relationship is expected to diminish over time as smaller players establish better trading relationships and adapt to the system (Connor and Alden 2001).

\section{RESULTS}

\section{Market dynamics}

In the initial year of ITQs there were a total of 378 quota accounts in the CRFFF, 374 of which held CT quota. By the beginning of 2005-2006 the total number of accounts had fallen to 329, with 293 of these holding CT quota (Fig. 3a). This reduction was mainly the result of some license owners selling the fishing entitlements they were awarded under the initial allocation process and contributed to the high volume of permanent trades also observed in the first year of ITQs (Fig. 2b). After 2005-2006, the number of accounts holding CT steadily increased again to 326 by 2009-2010, the year following the peak in landings, and has remained relatively flat since. Permanent trades of CT quota equated to $29 \%$ of the TAC in 2004-2005 but quickly fell to between $5 \%$ and $7 \%$ in subsequent years (Fig. 3c), comparable with the levels and trends observed for permanent transfers in other fisheries ITQ markets (Grafton 1996, Connor and Alden 2001, Kerr et al. 2004, Newell et al. 2005).

The proportion of account holders participating in the lease market, the overall volume of quota leased, and the numbers of temporary trades undertaken were all lowest in the first year of ITQs (Fig. 3). Participation and activity subsequently increased and peaked with landings in 2008-2009 before falling back closer 
Fig. 3. Trends in key descriptors of the coral trout (CT) quota lease market, 2004-2005 to 2011-2012: (a) number of accounts holding CT quota, landing CT, and involved in leasing, (b) number of trades, (c) quantity of quota traded as a percentage of the total allowable catch (TAC), (d) cumulative proportion of quota ownership vs cumulative proportion of account holders in which movement toward the bottom right corner indicates an increase in quota concentration.

a

— Hold CT quota $\cdots$... Land CT - - Lease trade

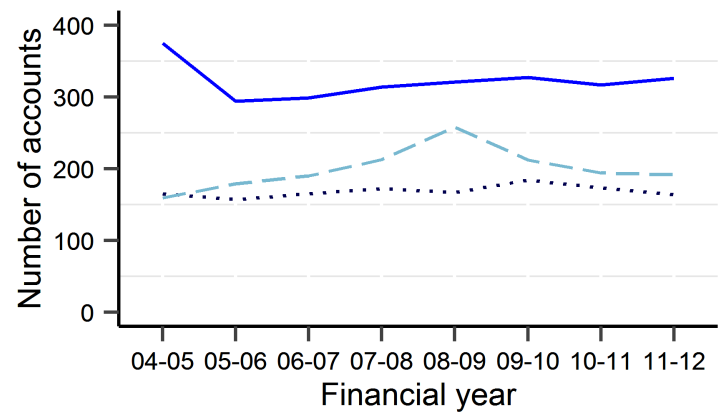

C

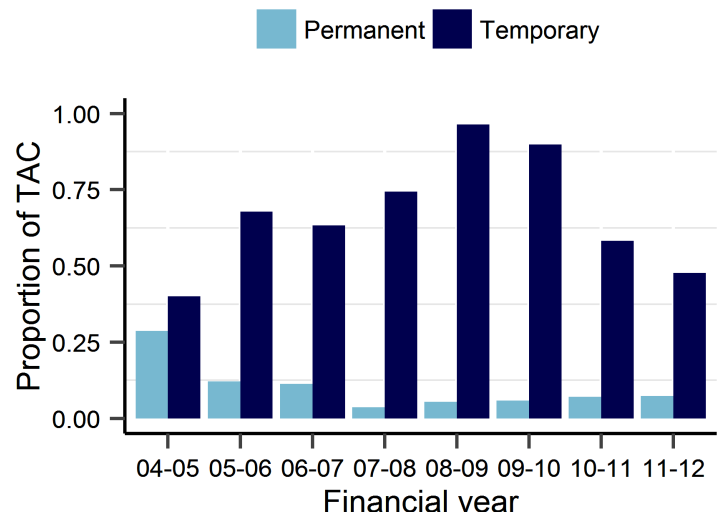

Financial year b

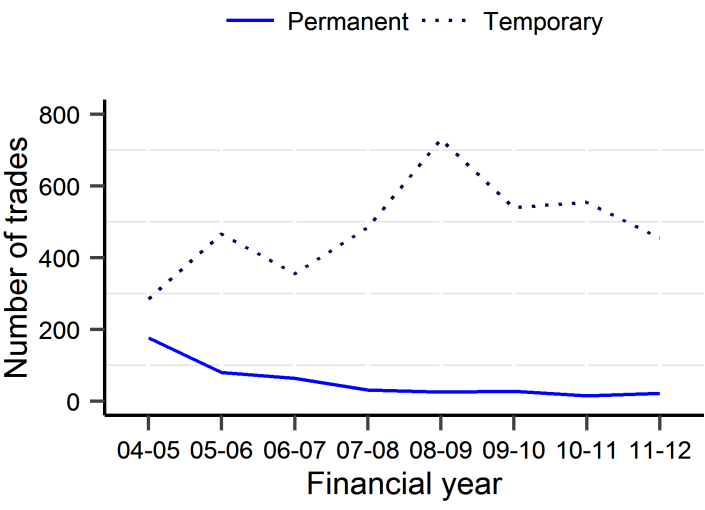

d to the levels observed in 2005-2006 (Fig. 3a,b). The proportion of accounts involved in lease trading peaked sharply at $80 \%$ in 2008-2009 (258 out of 320 accounts holding CT quota) but fell thereafter and have remained between $59 \%$ and $65 \%$ since. This is comparable with the $70 \%$ observed in New Zealand's quota market in 2000 (Newell et al. 2005), but somewhat lower than the 96\% seen in Australia's south east trawl fishery (SETF; Connor and Alden 2001).

The number of lease trades and the quantity of quota lease traded as a percentage of TAC increased between 2004-2005 and 2011-12 ( 285 to 455 and $40 \%$ to $48 \%$, respectively), but actually peaked with CT landings in 2008-2009 (at 730 and 96\%, respectively; Fig. $3 \mathrm{c})$. The proportion of TAC traded is a measure of market liquidity, calculated using the sum of all quota leased out (sold) over the year and therefore includes instances in which quota has been leased in (bought) and then leased out (sold) again in that same year. The proportion of TAC traded in 2011-2012 is broadly comparable with the $44 \%$ median seen in New Zealand (Newell et al. 2005), but lower than the $60 \%$ and $66 \%$ seen in the Tasmanian rock lobster fishery and the SETF, respectively (Connor and Alden 2001, van Putten et al. 2011). The Tasmanian rock lobster fishery quota market had been in existence for a comparable period of time when assessed, and although the proportion of quota leased increased less in the CT market, the number of transactions actually increased more $(\mathrm{CT}+60 \%$, rock lobster $+47 \%)$.

Given that the total volume of units leased increased proportionally less than the number of lease trades, the average size of CRFFF quota trades has fallen over time and by 2011-2012, the average CT lease trade was $25 \%$ smaller than in 2004-2005. Full time series for the measures of market dynamics are presented in Appendix 1.

Ownership of quota was relatively concentrated in 2004-2005 and has become increasingly so over time. The rate of concentration was greatest in the initial years of ITQ management, with the Gini coefficient for CT quota ownership increasing from 0.66 in 2004-2005 to 0.77 by $2008-2009$, after which it increased only 
Fig. 4. Network maps depicting the annual evolution of coral trout (CT) lease-trade relationships, 2004-2005 to 2011-2012. Circles denote quota redistributors that land more than one tonne of fish $(>1 \mathrm{t})$, triangles indicate quota redistributors that land less than one tonne of fish $(<1 \mathrm{t})$.

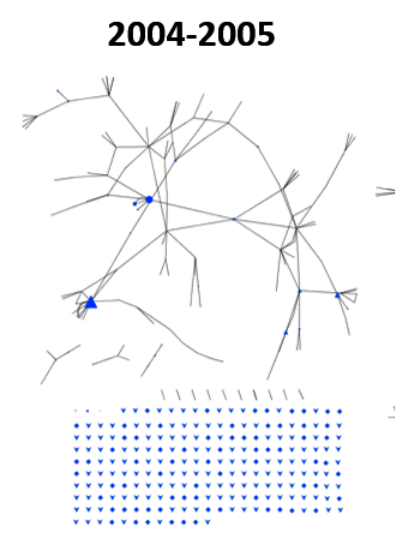

2008-2009

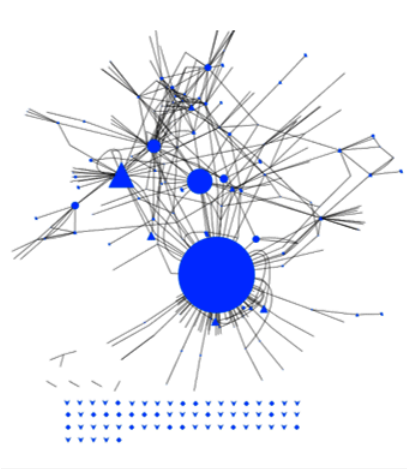

2005-2006

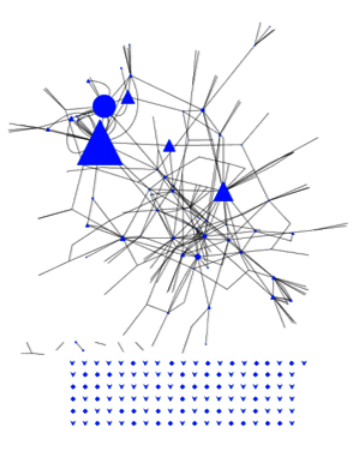

2009-2010

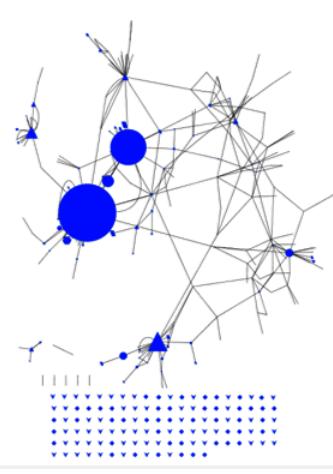

2006-2007

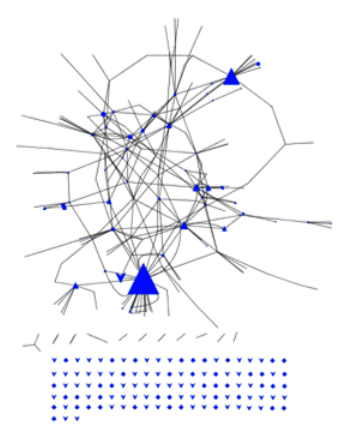

2010-2011

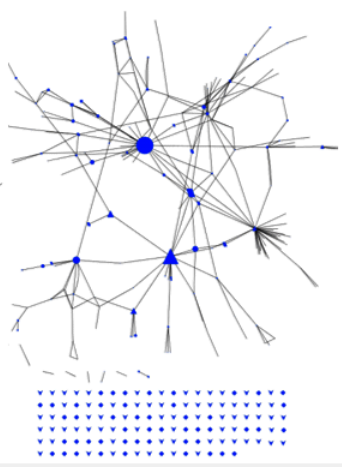

2007-2008

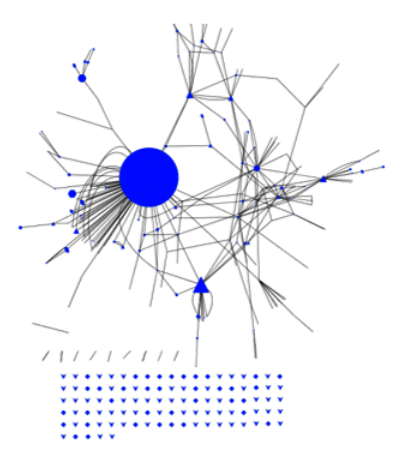

2011-2012 slightly to 0.78 by 2011-2012. To put it in context, this level of concentration is substantially higher than the 0.36 observed in the Tasmanian rock lobster after nine years of ITQ management (Hamon et al. 2009), in which the level of individual quota ownership is constrained. However, it is lower than the 0.97 seen in the New Zealand quota management system (QMS) for all finfish sectors combined, after a comparable period of existence (Connor 2001). The increase in concentration is also evident when we consider what proportion of quota was held by a given proportion of account holders over time. It can be seen in Figure $3 \mathrm{~d}$ that the greatest increase occurred between 2004-2005 and 2008-2009, with the curve for 2011-2012 differing little from 2008-2009. By 2011-12, the 10 largest quota owners accounted for $22 \%$ of CT TAC, which is again still well below the $83 \%$ observed in New Zealand's fin-fish fisheries by 1998 (Connor 2001).

\section{The coral trout (CT) quota leasing market as a network}

Each circular node in a CT quota lease network plot represents an individual quota account and the lines joining these nodes (edges) denote the existence of a direct lease trading relationship between the accounts in that year (Fig. 4.). The size of connected nodes reflects the total volume $(\mathrm{kg})$ of trade it was involved in over a year, both leasing in and out. The completely unconnected nodes at the bottom of each network map represent quota accounts that did not undertake any leasing activity that year.
These disconnected nodes correspond to operators who were identified as being either independent or inactive (as defined in Table 1). Of the 374 quota accounts present in the first year of ITQs, 173 were seen to still be present in some form by 2011-2012, meaning that over $50 \%$ of the original account holders exited the market in the period observed.

The network maps show a high number of nontraders in the first year (2004-2005). The trade network then developed, becoming more complex and incorporating an increasing number of participants until its peak in 2008-2009, after which it began to thin out again. Although the network was visibly sparser in 2011-2012 than 2008-2009, some of the structure can be seen to have remained when compared to 2004-2005, which had a higher proportion of terminal branches. A terminal branch is defined as a node with direct connections to only one other node.

\section{Network characteristics}

The network clustering coefficient, which indicates how dense the network is at the local level, is consistently close to zero (Table 2). Low clustering is generally considered atypical of real world networks as, for example, an individual's friends often are also friends with one another. Low connectivity was also observed between individual quota accounts and their neighbors in the Tasmanian rock lobster fishery (van Putten et al. 2011) and in the lease trade context, the low coefficient value indicated that the 
Fig. 5. Number of accounts with illustrated combinations of incoming (in-degree) and outgoing (out-degree) relationships for the CT lease trade market in 2004-05, 2008-09 and 2011-12.

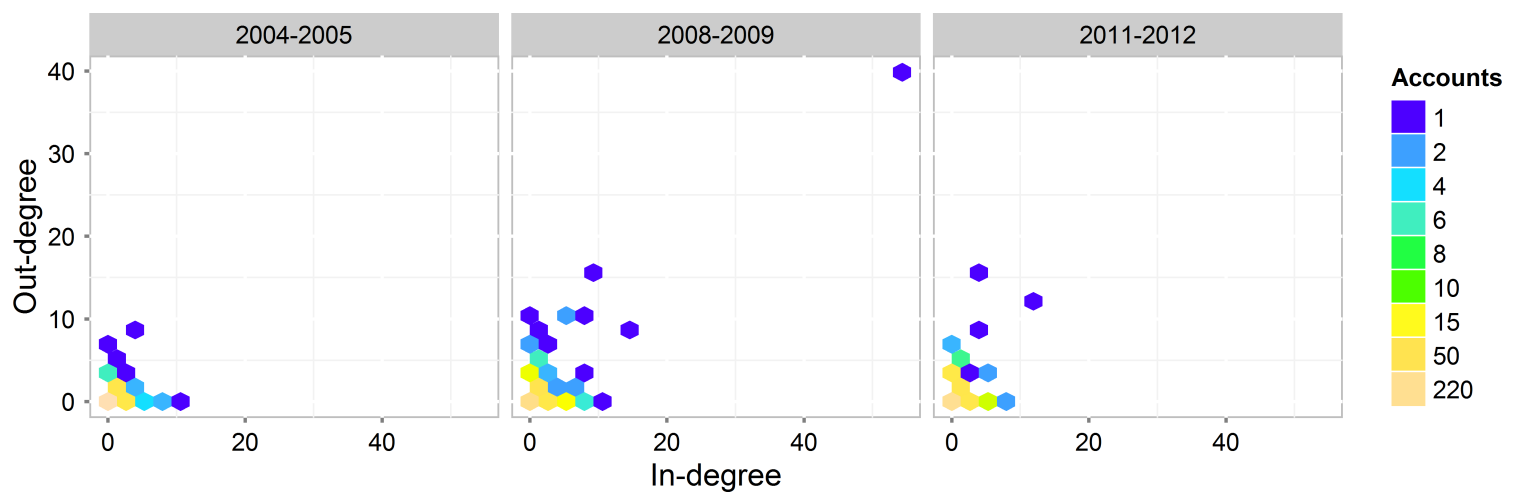

people an individual traded with did not also tend to trade with one another (an additional consequence of brokers in the market). The complexity of the CT lease trade market, as defined by its diameter, has typically been lower, between 3 and 10, than that seen in the rock lobster study, 4 to 11 . The CT network is seen to have been most complex in 2005-2006 (diameter 10), but became substantially less so by 2011-2012 (diameter 5), indicating a relatively less complex network and more direct routes between the most distant participants in the market.

Disregarding the first year because of the relatively small number of account holders participating in the market, the CT lease network became more compact over time as the length of the average shortest trading connections between any two participants decreased. This change is illustrated by the characteristic path length (CPL) of the network falling from 3.36 in 2005-2006 to 1.98 in 2011-2012 (Table 2). The initial increase in CPL from 1.47 to 3.36 between 2004-2005 and 2005-2006 was likely a result of the increasing number of market participants over the same period and the absence of hub-forming, brokertype nodes, which reduce average path lengths between nodes. A similar magnitude increase was observed in the rock lobster fishery and attributed to increasing numbers of quota owners having high numbers of connections.

Changes in how account holders were positioned in the network are picked up in the measures of betweenness and closeness centrality. The proportion of nodes that formed bridges between other nodes, i.e., betweenness centrality $>0$, was seen to follow the general trend of greatly increasing by the second year of quotas before peaking in 2008-2009 and then falling away again. This change, along with a similar reduction in the proportion of nodes with closeness centrality scores $>0$, indicates an effective fragmentation of the network after 2008-2009 as greater proportions of account holders stopped participating in the lease trade network.

\section{Broker nodes}

The CT lease trade market is a directed network, meaning that relationships are not necessarily symmetrical, i.e., trader A may lease to trader B but B does not lease to A. The number of trading relationships an account holder has (degree) can thus be assessed by counting either the number of other account holders they lease quota in from (in-degree), or the number of account holders they lease quota out to (out-degree). The frequencies of different levels of in-degree and out-degree, in terms of number of accounts, are plotted for the CT lease trade network in Figure 5.

The distributions are similar in shape across all years and relationship directions (Fig. 5). All fit well to a power-law $\left(\mathrm{R}^{2}>\right.$ 0.77; Equation 1 and Table A1.1 in Appendix 1), indicating that the network is scale-free in nature, i.e., many account holders have few connections $(\leq 1)$ and only a few have many connections. This distribution also suggests that the most likely point of entry to the network for a disconnected account holder is via already wellconnected broker nodes (Barabási and Albert 1999). In 2004-2005, only $20 \%$ of account holders had inbound leasing connections (in-degree $>0$ ), $29 \%$ had outbound connections (outdegree $>0$ ), and most of these were only connected to one other account holder (in-degree $=1 ; 50 \%$ of the account holders with in-degree $>0,75 \%$ of the account holders with out-degree $>0$ ). The proportions of account holders with lease-trading relationships increased to their maximum in 2008-2009 when nearly half of the account holders had incoming relationships ( $42 \%$ with in-degree $>0)$, and even more had relationships leasing quota out $(55 \%$ with out-degree $>0)$. It should be noted that account holders without lease-trading relationships in at least one of the directions, i.e., either an in-degree of zero or an out-degree of zero, always formed the largest individual group in each year. If account holders did lease quota they tended to either lease quota in or out, but not do both.

The major differences between the distributions of trade relationships are in the most highly connected accounts for each time period. The highest numbers of trading relationships market participants had in the first year of trading were 10 in-degree and 8 out-degree (Fig. 5). By 2008-2009, this had increased to 53 and 40 , for in- and out-degrees, respectively. The gap between the most highly connected account holders and the account holder with the next highest number of connections is apparent in all years, particularly in 2008-2009, and the proportion of account holders with a degree greater than or equal to 4 never exceeded $10 \%$ of the total number of account holders.

\section{Individual strategies on the quota market}

Investors owned the greatest quantity of quota in 2011-2012 (532,747 units), whereas lease-dependent fishers accounted for the majority of landings (496 tonnes; Fig. 6). The role of investors 
Fig. 6. Proportional coral trout (CT) quota ownership and landings at the group level. Ownership presented as a proportion of the CT total allowable catch (TAC), landings as a proportion of total CT landings, for each year considered.

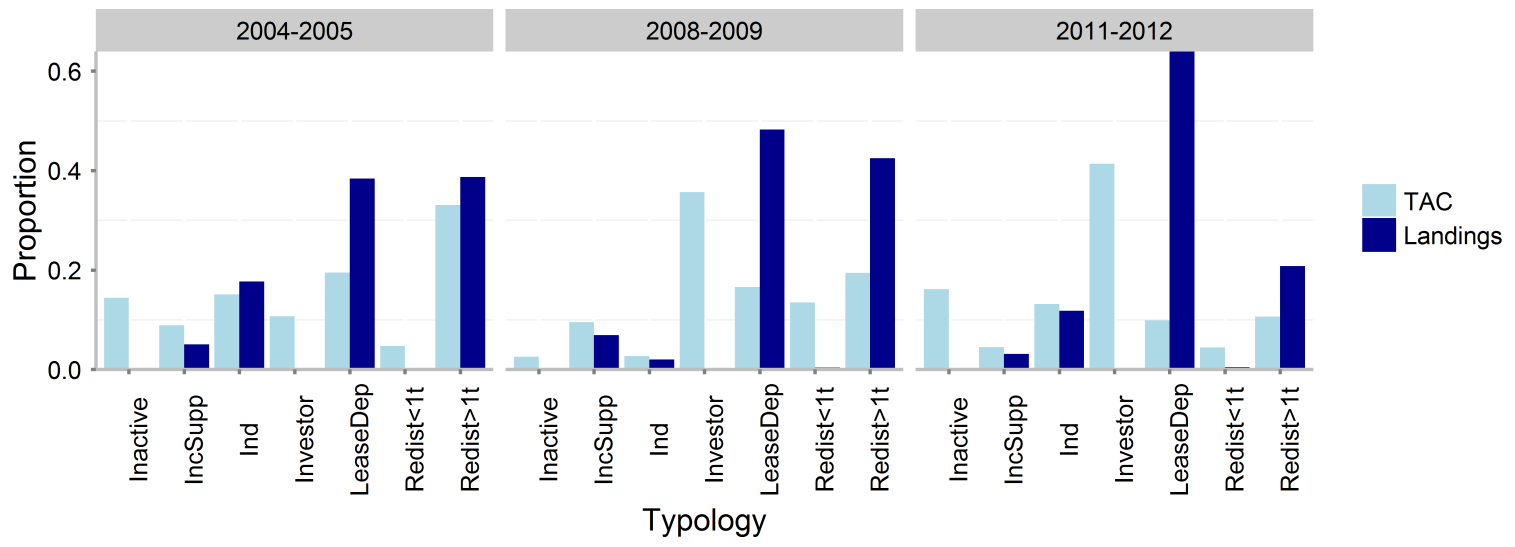

as 'owners' and lease dependent fishers as 'catchers' developed over time with investor holdings increasing from $10 \%$ of the CT TAC in $2004-2005$ to $41 \%$ by $2011-2012$, and the proportion of CT landings attributed to lease-dependent fishers rising from $38 \%$ in 2004-2005 to $64 \%$ by 2011-2012. The interdependent relationship that exists between investors, who depend upon leasedependent fishers to lease their quota, and the lease-dependent fishers, who require investor quota to operate, can be seen through their trade relationship. Investors leased $62 \%, 45 \%$, and $63 \%$ of their quota to lease-dependent fishers in 2004-2005, 2008-2009, and 2011-2012, respectively. The remainder went to the two quota redistributor groups.

The observed roles of the two types of quota redistributors vary. As a group, quota redistributors that landed over one tonne of CT per year reduced their ownership of TAC over time but their landings varied with total catches. Their landings increased in 2008-2009 following the fishery's peak in catches and then declined following the general reduction in catches. Quota redistributors that landed less than one tonne of CT behaved more like brokers than fishers. Their ownership of quota increased and then decreased with fishery-level landings, and they leased this quota out rather than landed fish against it. Their role in the quota-leasing network is explored further below.

The number of independent operators fell between the years 2004-2005 and 2008-2009 (71 to 21) as the CT TAC came close to being reached and fishery conditions required these operators to lease quota in. This trend then reverted, and the number of independent operators increased to 46 by 2011-2012, as the gap between total fishery catches and the TAC increased once again. Income supplementers maintained the quota they owned and slightly increased catches during the peak year relative to 2004-2005, but then reduced their TAC ownership and landings when catches declined.

Finally, a large proportion $(40 \%, 148)$ of accounts was inactive in 2004-2005, meaning that these quota owners neither leased nor caught any part of their quota during the year. This inactive component was substantially smaller by $2008-2009(14 \%, 46)$, but was relatively large again by $2011-2012(30 \%, 96)$.

\section{Box 1:}

Of the businesses that were inactive in 2004-2005, 110 had left the system by 2011-2012, assumed to have sold out entirely; 24 were still inactive; 6 had become independent operators, i.e., they had started fishing their quota only; 5 had become investors so were now leasing their quota out; and 3 had become lease dependent so were now catching and landing CT and leasing some quota in. Of the 24 accounts that were inactive in both the first and last year, $67 \%$ had been allocated the default minimum of 800 units in the first year of ITQs.

Inactive accounts held just over $1 \%$ of the CT TAC (15,191 units) between them in 2008-2009 and this is broadly comparable to the $4 \%$ of TAC observed to be held inactive in the SETF in 1998 (Connor and Alden 2001). The volume of inactive quota then increased six fold to over 208 tonnes in 2011-2012, meaning that quota equivalent to $\sim 16 \%$ of the CT TAC was not fished or traded in that year. At the individual level, average holdings of an inactive quota account were just under 0.7 tonnes in 2008-2009, and increased to 2.2 tonnes in 2011-2012 when demand for CT quota was weaker.

\section{Measuring market functionality}

Larger quota holders generally came closest to balancing their accounts in all years, with a positive correlation being observed between the quantity of quota that accounts held and how close they came to balancing their account by the end of the year. This relationship also actually strengthened over time, going from 0.20 in 2004-2005 to 0.27 in 2008-2009 and 2011-2012 (Fig. 7), contrary to the a priori expectation that any such asymmetry would diminish as smaller account holders became better informed and adapted to the system.

In 2004-2005, many account holders failed to use the entire quota they held in their accounts. The average gap was $52 \%$, i.e., $52 \%$ of quota held was not used, and even the two largest quota holders finished the year with gaps of close to $20 \%$ (Fig. 7). By 2008-2009, 
Fig. 7. Coral trout (CT) quota held compared to quota used at the individual account holder level in three separate financial years with horizontal broken lines denoting usage at $80 \%$ and $100 \%$ (gaps of $20 \%$ and $0 \%$, respectively). The correlation coefficient between proportion of quota held and size of gap observed is given for each year in bold.

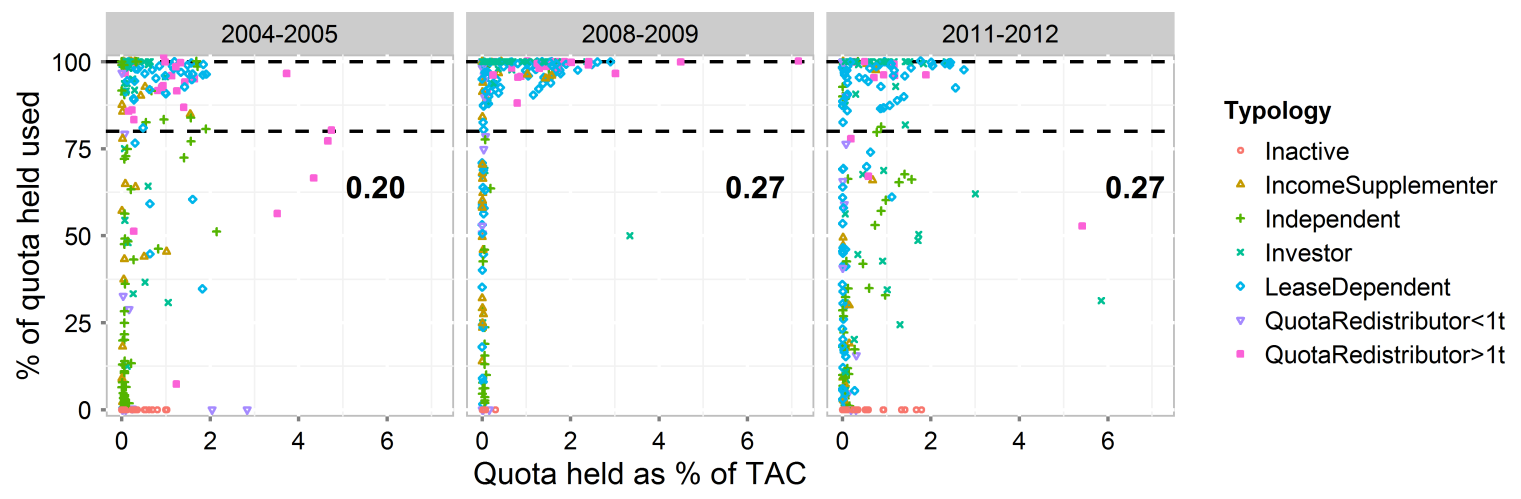

most quota holders were substantially closer to balancing their accounts. Accounts holding more than a small percentage of quota, defined here as those individually holding $>0.1 \%$ of the TAC, had reduced their gap to less than $10 \%$, with an average of only $3 \%$. Smaller account holders, those individually holding $\leq$ $0.1 \%$ of the TAC, also reduced their average gap in this period to $28 \%$, equating to an average of 200 units. That, along with inactive quota being at an all-time low of $3 \%$, seems to suggest that the market functioned reasonably well in this period. In the last year of data, 2011-2012, the effects of the post 2008-2009 declines in landings and the consequent slackening in demand for quota are apparent and can be seen to have negatively affected quota holders of all magnitudes, with the prevalence and size of gaps increasing once again. The operator types most vulnerable to this were the independent fishers, who did not lease quota out, so did not adjust to reduced levels of landings, and investors who directly suffered from the low demand for quota associated with low catches.

The groups with the consistently smallest gaps were the leasedependent fishers and the quota redistributors that landed $>1$ tonne of fish. As both these groups generally owned fewer quota units than they required, they had greater capacity to balance their accounts when the fishing was worse. Lease-dependent fishers could simply lease fewer quota units in. Quota redistributors $>1$ tonne, being active fishers, were also better able to catch the quota they owned while making leasing decisions based on the strength of market demand and supply at any particular point in time, reducing the likelihood of being left with unused quota in the process. Groups such as the investors did not have the ability to do this in the short run.

\section{DISCUSSION AND CONCLUSIONS}

We carried out a detailed analysis of the evolution of the coral trout quota market, following its establishment as part of the regulatory management of the Queensland CRFFF. Our analysis shows that after an initial period of adjustment in 2004-2005, when a number of license owners sold the quota they had been awarded, network measures indicated that the lease market for CT quota grew and developed until 2008-2009. As the fishery came closer to reaching the TAC, leasing activity increased substantially and highly connected broker-type operators, who facilitated quota redistribution, emerged in the marketplace. A number of these were essentially dedicated brokers who landed little or no fish themselves (quota redistributors $<1$ tonne). At the same time, large lease-dependent operators started needing to lease quota from a greater number of sources than they had previously, becoming more connected in the process and further contributing to the observed change in network structure.

The scale-free nature of the market suggests that account holders entering the lease trade market are most likely to join via one of the already well connected broker nodes (Barabási and Albert 1999). Given that the scale-free character of a network is also usually assumed to increase as a network evolves, the observation that already connected quota accounts became increasingly connected in periods with increased market participation was expected. This occurred in the CT lease market when more favorable bioeconomic conditions resulted in high demand for quota and a thinning supply, so more operators were encouraged to either catch their quota, possibly even leasing additional quota in, or to lease it out. Leasing quota required new trading relationships to be established and instead of each individual account holder forming lease-trade relationships with others in a similar situation, they were generally observed to form a relationship with one of the broker-type account holders. The higher transaction costs almost certainly associated with typically poorly connected individual traders having to first identify, then negotiate, and trade with one another are likely to have driven this. Anecdotal evidence collected during conversations with fishers in the CRFFF (Thébaud et al. 2014) also suggests that in some cases the anonymity that using a broker provided could contribute to their attractiveness as it prevented individuals from having to deal directly with prospective lessors/leasees they may have known and felt uncomfortable having to bargain with.

After 2008-2009, the general fall in landings reduced demand for leased quota and the lease-trade network partially disbanded as a result. The structure of the market did not reduce in a uniform manner because after 2008-2009, well-connected accounts 
Table 2. Selected statistics for the coral trout (CT) lease trade network.

\begin{tabular}{lcccccccc}
\hline \hline Network statistic & $2004-2005$ & $2005-2006$ & $2006-2007$ & $2007-2008$ & $2008-2009$ & $2009-2010$ & $2010-2011$ & $2011-2012$ \\
\hline Number of nodes & 374 & 293 & 298 & 313 & 320 & 326 & 316 & 325 \\
Number of edges & 161 & 272 & 273 & 279 & 390 & 287 & 255 & 243 \\
Clustering coefficient & 0.006 & 0.031 & 0.021 & 0.019 & 0.033 & 0.034 & 0.015 & 0.015 \\
Network diameter & 3 & 10 & 9 & 8 & 8 & 5 & 6 & 5 \\
Characteristic path length & 1.471 & 3.355 & 2.808 & 2.834 & 2.894 & 2.456 & 2.331 & 1.984 \\
Network density & 0.000 & 0.000 & 0.000 & 0.000 & 0.000 & 0.000 & 0.000 & 0.000 \\
Betweenness centrality $>0$ & 0.051 & 0.112 & 0.124 & 0.115 & 0.128 & 0.101 & 0.073 & 0.077 \\
Closeness & 0.289 & 0.486 & 0.438 & 0.433 & 0.553 & 0.379 & 0.331 & 0.314 \\
centrality $>0$ & & & & & & & & \\
\hline
\end{tabular}

reduced the number of other operators they leased quota from to a higher degree than they reduced those they leased out to. In particular, lease-dependent operators no longer needed to source quota from multiple other smaller quota owners (i.e. demand driven), and broker-type nodes could satisfy outgoing quota demands with fewer incoming relationships. When required, these incoming relationships were generally formed with fewer, and larger quota holders. The role of broker nodes as suppliers of quota, with many outward connections, did not reduce to the same extent by 2011-2012.

It appears that the extent to which hubs play an important role as brokers varies with the circumstances of the fishery. In a slack market, people are likely to know enough about the immediate supply and demand of quota to satisfy their needs. In a tighter market, this may not be enough and recourse to brokerage services might develop, thus increasing the importance of certain key nodes. The impact on demand for quota of fluctuations in total annual landings is even more pronounced in this fishery due to the TAC being static over time. As the TAC has not historically adjusted to reflect the fishery's biological/economic conditions, this will naturally have contributed to the level of inactive quota when the TAC was not met.

Given the observation that being highly connected resulted in account holders becoming even more connected when demand for quota was high, we used the lease-trade data to look for any evidence that being highly connected could be advantageous in periods of lower quota demand. The assumption being that greater demand connectivity may assist these account holders in leasing their quota out ahead of less connected account holders. The quota transaction data in the periods following 2008-2009 do not appear to support this, and there is no obvious evidence that that these account holders were able to capitalize on preexisting relationships when there was less demand for quota.

The overall fall in CT lease-trade network complexity, indicated by a reduced diameter measure, contradicts what was observed in the Tasmanian rock lobster ITQ market, whose diameter increased as it became more complex over the period assessed. This variation is most likely related to differences in the rules governing quota ownership and trade in the two fisheries, with Queensland regulations allowing for broker-type activity to develop as well as greater concentration of ownership. As seen in Figure $3 \mathrm{~d}$, the CT quota market is relatively concentrated.

Another important finding from this analysis was the amount of quota that was held inactive in most years, being neither fished nor traded. Over the last three years of data, inactive accounts alone held quota ranging between $5-16 \%$ of the TAC. The existence of so-called 'sleeper holdings' was also observed in the SETF and ranged between $1.5 \%$ and $9 \%$ of the allocated TAC over the period for which this was observed. It was $4 \%$ in the last year assessed (Connor and Alden 2001). According to our analysis, sleeper holdings in the CRFFF were of a similar magnitude $(1.2 \%)$ in the peak year, but somewhat higher more recently $(16 \%)$.

Despite substantial quantities of inactive quota existing in the fishery, advertised lease prices were not seen to fall below A \$1 per unit at any point in this period and were still as high as $\mathrm{A} \$ 3.50$ early in 2011-2012 (Thébaud et al. 2014). Theory suggests that quota should not go unused so long as the market price remains positive (Arnason 1990), making the degree of inactivity that persisted throughout the 2004-2012 period, alongside an active market and positive prices, appear somewhat contrary to expectations. This is especially so if we consider that in addition to the opportunity cost of not doing anything with the quota, owners incur an annual fee of A $\$ 0.33$ per unit of quota owned, levied independent of whether the units they own are fished. Leaving opportunity costs aside, the rational expectation is that quota owners should be prepared to reduce the lease price of their quota to the point at which at least the cost of owning it (A $\$ 0.33)$ and any transaction costs associated with leasing it out are met. If it can be assumed that this is the case in the CRFFF, and that as a result $\sim \mathrm{A} \$ 1$ per unit represented a net price of approximately zero in 2011-2012, then nontrivial transaction costs are likely to exist. Package trading of quota, in which more than one form of quota (CT, RTE, or OS) is leased in the same transaction, has been observed in this fishery and also suggests the presence of transaction costs (Innes et al. 2014).

Although undesirable, some level of transaction cost is common, and significant transaction costs have previously been observed in markets for a number of tradable permits (Stavins 1995) and were estimated to range between $15-22 \%$ of mean discounted net returns in the Dutch phosphate quota program (Wossink and Gardebroek 2006). In the fisheries context, transaction costs in the form of brokerage fees are reported to have ranged between $1-3 \%$ of transaction value in New Zealand (Newell et al. 2005). Conversations with a broker of RQ quota suggest that fees in this fishery generally range between $8-15 \%$ of the value of a transaction. However, smaller transactions, e.g., 400 units, may instead incur a flat rate of $\mathrm{A} \$ 100-150$, resulting in transaction fees in the region of $25-38 \%$. In this instance, the unit value of 
quota is effectively devalued to A $\$ 0.63-0.75$ because these fees are always paid by the quota owner. When considered in combination with our results relating to inactive quota and lease prices, this suggests that transaction costs are relatively high in this quota market. If the practice of levying a flat fee on small transactions is commonplace, small quota owners will be subject to the highest transaction fees relative to the value of quota traded, giving them possibly even less incentive to lease their quota out.

One consequence of relatively high transaction costs is that they effectively prevent the price of quota from adjusting down to a level at which it may still trade, even when the bioeconomic situation of the fishery has degraded. Lease prices can then remain above what potential leasees perceive it to be worth at that point in time, and this ultimately results in fewer quota units being traded and used than would have otherwise. Inadequate program design, which resulted in increased trading costs, was found partially to blame for nontrading in five nutrient trading programs in the U.S. (Hoag and Hughes-Popp 1997). As lease-dependent fishers were responsible for 64\% of all CT landed in 2011-2012, and $83 \%$ of this catch was landed using quota that they had leased in, lease prices are an important component of the variable costs these operators face. Anything that keeps the price of quota higher than it would be in a well-functioning system may thus impose significantly higher operating costs on these fishers. Asymmetries in the relative size of transaction costs, such as when costs are invariant of transaction size, e.g. search costs, further disadvantage smaller account holders by making it comparatively more costly for them to trade quota. This is likely to have contributed to the relatively high average gap size observed for smaller operators, even in times of high demand.

Results from the market functionality analysis show that smaller quota holders, defined as those individually holding $\leq 0.1 \%$ of the TAC (equating to roughly 12 tonnes of quota), accounted for $58 \%$ of accounts in 2008-2009, but still had an average gap of $28 \%$ in that year. By comparison, accounts holding $>0.1 \%$ of TAC had an average gap of only $3 \%$ in 2008-2009, implying a scale effect. That smaller quota holders appear to consistently finish the year with less well balanced accounts, despite favorable biological and economic conditions leading to a high demand for quota, suggests that asymmetries in information and transaction costs persisted in 2008-2009 and affected smaller account holders more strongly. Asymmetric information, market power residing with larger quota holders and processors, who also typically have better access to capital, has also been raised as an issue in other ITQ managed fisheries (Pinkerton and Edwards 2009). It is also likely that there is significant option value, i.e., the value associated with preserving something despite possibly not intending to use it in the short term, associated with retaining some quota. This would also be more likely with smaller account holders if transaction costs exist and a component of these costs is invariant to transaction size.

More work is required to identify the factors that influence trade patterns and determine the structure of the CT quota market. This includes factors such as the geographical distribution of account holders that actively fish, and whether they operate from the same ports or fishing areas as brokers. It also includes the individual-level factors that drive different operators to adopt alternative strategies with respect to quota ownership and trading, as well as fishing against their quota.
Based on the results of our analysis, it appears that both smaller quota holders and overall market efficiency could benefit from actions that reduce market asymmetries and the transaction costs of quota trading (Stavins 1995). The CRFFF quota market currently operates via a QDAFF administered FishNet website, which allows registered account holders to perform temporary transfers of quota and to view quota usage statements and balances (quantities only). However, the extent to which trading partners are identified via this platform is unknown. Anecdotal information obtained during a recent economic survey of the fishery (Thébaud et al. 2014) suggests that account holders, and particularly the smaller ones, are most likely to contact individuals that they are familiar with within their local fishing network in the first instance. Collecting and regularly publishing data relating to the prices being paid for quota could help reduce the level of uncertainty in prices. This is a standard feature of the New Zealand quota management system (through FishServe). The ability to pool quota, an approach also suggested for the SETF (Connor and Alden 2001), would assist smaller quota holders to overcome issues of transaction costs when the volume of quota held is relatively small at the individual level.

These findings also raise questions around how quota is initially allocated in ITQ managed fisheries. Although it has been argued that grandfathering catch rights to historical participants is the most efficient allocation mechanism (Anderson et al. 2011), it has also been shown that if the transaction costs of subsequent exchanges are high it is generally preferable to assign rights to low-cost fishery participants (Libecap 2007). In the absence of tools to reduce asymmetries in costs, such as quota pooling, approaches that aim to be equitable by allocating small quantities of quota to many smaller fishery participants for whom transaction costs are relatively high, could therefore actually be detrimental and inadvertently result in long run inefficiency. If high transaction costs prevent the price of quota from adequately adjusting, unnecessary additional costs will be imposed upon the component of the fishery that lands the majority of its fish. If no longer fishing themselves, small quota holders will also be less able to capitalize on their quota assets if transaction costs reduce their ability/willingness to lease it out.

Beyond the CRFFF, our analysis demonstrates the importance of the collection and in-depth analysis of fishing quota market data. Our understanding of the real-world characteristics of these market-based approaches to allocating access rights in fisheries and our evaluation of the key determinants of their efficiency depends upon the collection and analysis of data. The findings of this case study also illustrate that if transaction costs exist and the number of small quota holders is relatively large 'sleeper holdings' are likely to exist and will be more pronounced when the bioeconomic situation of the fishery is worse. Because the majority of catch is often taken by a relatively small proportion of a fishery's vessels, the widely applied management approach of initially allocating quota based on historical catches will also contribute to this situation. Overall, these findings lend weight to the view (Stavins 1995) that grandfathering may not be neutral with respect to market efficiency in such systems.

Responses to this article can be read online at: http://www.ecologyandsociety.org/issues/responses. $\mathrm{php} / 6637$ 


\section{Acknowledgments:}

The authors acknowledge financial support from the CSIRO Wealth from Oceans Flagship and the FRDC project 2011/030 "Evaluating Candidate Monitoring Strategies, Assessment Procedures and Harvest Control Rules in the Spatially Complex Queensland Coral Reef Fin-Fish Fishery." We are also grateful for the advice and comments on earlier versions of this work provided by Sean Pascoe, John Kung, and Brigid Kerrigan. Additional background information and advice was also provided by Tom Roberts in relation to the RQ market, and Nadia Engstrom and Susan Theiss of QDAFF assisted in providing us with the quota trading data. Finally, the constructive comments of two anonymous reviewers are also gratefully acknowledged. Any remaining errors or omissions are the sole responsibility of the authors.

\section{LITERATURE CITED}

Anderson, L. G. 1991. A note on market power in ITQ fisheries. Journal of Environmental Economics and Management 21 (3):291-296. http://dx.doi.org/10.1016/0095-0696(91)90032-E

Anderson, L. G. 2008. The control of market power in ITQ fisheries. Marine Resource Economics 23(1):25-35.

Anderson, T., R. Arnason, and G. D. Libecap. 2011. Efficiency advantages of grandfathering in rights-based fisheries management. Annual Review of Resource Economics 3 (1):159-179. http://dx.doi.org/10.1146/annurev-resource-083110-120056

Arnason, R. 1990. Minimum information management in fisheries. Canadian Journal of Economics 23(3):630-653. http://dx. doi.org/10.2307/135652

Arnason, R. 1993. The Icelandic individual transferable quota system: a descriptive account. Marine Resource Economics 8 (3):201-218. [online] URL: http://innri.unuftp.is/fppreadings/ arnason_r_1993-b.pdf

Arnason, R. 2012. Property rights in fisheries: how much can individual transferable quotas accomplish? Review of Environmental Economics and Policy 6(2):217-236. http://dx.doi. org/10.1093/reep/res011

Assenov, Y., F. Ramírez, S.-E. Schelhorn, T. Lengauer, and M. Albrecht. 2008. Computing topological parameters of biological networks. Bioinformatics 24(2):282-284. http://dx.doi.org/10.1093/ bioinformatics/btm554

Barabási, A.-L. 2005. Network theory - the emergence of the creative enterprise. Science 308(5722):639-641. http://dx.doi. org/10.1126/science.1112554

Barabási, A.-L. 2009. Scale-free networks: a decade and beyond. Science 325(5939):412-413. http://dx.doi.org/10.1126/science.1173299

Barabási, A.-L., and R. Albert. 1999. Emergence of scaling in random networks. Science 286(5439):509-512. http://dx.doi. org/10.1126/science.286.5439.509

Barnes-Mauthe, M., S. Arita, S. D. Allen, S. A. Gray, and P. Leung. 2013. The influence of ethnic diversity on social network structure in a common-pool resource system: implications for collaborative management. Ecology and Society 18(1): 23. http:// dx.doi.org/10.5751/ES-05295-180123
Chu, C. 2009. Thirty years later: the global growth of ITQs and their influence on stock status in marine fisheries. Fish and Fisheries 10(2):217-230. http://dx.doi.org/10.1111/j.1467-2979.2008.00313. $\underline{\mathrm{x}}$

Clark, C. W. 1980. Towards a predictive model for the economic regulation of commercial fisheries. Canadian Journal of Fisheries and Aquatic Sciences 37:1111-1129. http://dx.doi.org/10.1139/ $\underline{\text { 880-144 }}$

Connor, R. 2001. Changes in fleet capacity and ownership of harvesting rights in New Zealand fisheries. Pages 151-185 in R. Shotton, editor. Case studies on the effects of transferable fishing rights on fleet capacity and concentration of quota ownership. FAO Fisheries Technical Paper 412. Food and Agriculture Organization, Rome, Italy. [online] URL: http://www.fao.org/ docrep/005/y2498e/y2498e00.htm

Connor, R., and D. Alden. 2001. Indicators of the effectiveness of quota markets: the South East trawl fishery of Australia. Marine and Freshwater Research 52(4):387-397. http://dx.doi. org/10.1071/MF99164

Department of Empoyment, Economic Development and Innovation (DEEDI). 2011. Annual status report 2010 coral reef fin fish fishery. Department of Empoyment, Economic Development and Innovation, Brisbane, Queensland, Australia. [online] URL: http://www.environment.gov.au/system/files/ pages/959be80b-5bc8-4d52-baee-b84042801778/files/coral-reef-finfish-status-report-2011.pdf

Department of Primary Industries (DPI). 2003. Fisheries (coral reef fin fish) management plan 2003. Department of Primary Industries, Government of Queensland, Brisbane, Queensland, Australia. [online] URL: https://www.legislation.qld.gov.au/ LEGISLTN/CURRENT/F/FisherCRFFMP03.pdf

Erdős, P., and A. Rényi. 1959. On random graphs. Publicationes Mathematicae Debrecen 6:290-297. [online] URL: http://ftp. math-inst.hu/ p erdos/1959-11.pdf

Farrell, J. 1987. Information and the Coase Theorem. Journal of Economic Perspectives 1(2):113-129. http://dx.doi.org/10.1257/ jep.1.2.113

Great Barrier Reef Marine Park Authority (GBRMPA). 2004. Great Barrier Reef Marine Park zoning plan 2003. Great Barrier Reef Marine Park Authority, Townsville, Queensland, Australia. [online] URL: http://www.gbrmpa.gov.au/_data/assets/pdf_file/0015/3390/ GBRMPA-zoning-plan-2003.pdf

Gini, C. 1921. Measurement of inequality of incomes. Economic Journal 31:124-126. http://dx.doi.org/10.2307/2223319

Grafton, R. Q. 1996. Individual transferable quotas: theory and practice. Reviews in Fish Biology and Fisheries 6(1):5-20. http:// dx.doi.org/10.1007/BF00058517

Grafton, R. Q., D. Squires, and K. J. Fox. 2000. Private property and economic efficiency: a study of a common-pool resource. Journal of Law and Economics 43(2):679-713. http://dx.doi. org/10.1086/467469

Grimm, D., I. Barkhorn, D. Festa, K. Bonzon, J. Boomhower, V. Hovland, and J. Blau. 2012. Assessing catch shares' effects evidence from federal United States and associated British 
Columbian fisheries. Marine Policy 36(3):644-657. http://dx.doi. org/10.1016/j.marpol.2011.10.014

Hamon, K. G., O. Thébaud, S. Frusher, and L. Richard Little. 2009. A retrospective analysis of the effects of adopting individual transferable quotas in the Tasmanian red rock lobster, Jasus edwardsii, fishery. Aquatic Living Resources 22(04):549-558. http://dx.doi.org/10.1051/alr/2009039

Hartley, M., and M. Fina. 2001. Changes in fleet capacity following the introduction of individual vessel quotas in the Alaskan pacific halibut and sablefish fishery. FAO Fisheries Technical Paper 186-207.

Hatcher, A., S. Jaffry, O. Thébaud, and E. Bennett. 2000. Normative and social influences affecting compliance with fishery regulations. Land Economics 76(3):448-461. http://dx.doi. org/10.2307/3147040

Haythornthwaite, C. 1996. Social network analysis: an approach and technique for the study of information exchange. Library and Information Science Research 18(4):323-342. http://dx.doi. org/10.1016/S0740-8188(96)90003-1

Herrmann, M. 1996. Estimating the induced price increase for Canadian Pacific halibut with the introduction of the individual vessel quota program. Canadian Journal of Agricultural Economics 44(2):151-164. http://dx.doi.org/10.1111/j.1744-7976.1996. $\underline{\mathrm{tb} 00190 . \mathrm{x}}$

Hoag, D. L., and J. S. Hughes-Popp. 1997. Theory and practice of pollution credit trading in water quality management. Applied Economic Perspectives and Policy 19:252-262. http://dx.doi. org/10.2307/1349740

Innes, J., O. Thébaud, A. Norman-López, L. Richard Little, and J. Kung. 2014. Evidence of package trading in a mature multispecies ITQ market. Marine Policy 46:68-71. http://dx.doi. org/10.1016/j.marpol.2013.12.013

Jackson, M. O. 2011. An overview of social networks and economic applications. Pages 511-585 in J. Benhabib, A. Bisin, amd M. O. Jackson, editors. The handbook of social economics Elsevier, London, UK. http://dx.doi.org/10.1016/ B978-0-444-53187-2.00012-7

Kerr, S., R. G. Newell, and J. Sanchirico. 2004. Evaluating the New Zealand individual transferable quota market for fisheries management. Pages 121-134 in T. Tietenberg and N. Johnstone, editors. Tradeable permits: policy evaluation, design and reform. Organisation for Economic Co-operation and Development (OECD), Paris, France. http://dx.doi.org/10.1787/9789264015036-6en

Knapp, G. 1997. Initial effects of the Alaska halibut ITQ program: survey comments of Alaska fishermen. Marine Resource Economics 12:239-248.

Kroetz, K., and J. N. Sanchirico. 2010. Economic insights into the costs of design restrictions in ITQ programs. RFF Report. Resources for the Future, Washington, D.C., USA. [online] URL: http://www.rff.org/rff/documents/rff-rpt-kroetzsanchirico.pdf

Libecap, G. D. 2007. Assigning property rights in the common pool: implications of the prevalence of first-possession rules for
ITQs in fisheries. Marine Resource Economics 22:407-423. [online] URL: http://www2.bren.ucsb.edu/ glibecap/MarineResourcEconomics. pdf

Lindner, R. K., H. F. Campbell, and G. F. Bevin. 1992. Rent generation during the transition to a managed fishery: the case of the New Zealand ITQ system. Marine Resource Economics 7 (4):229-248.

Moloney, D. G., and P. H. Pearse. 1979. Quantitative rights as an instrument for regulating commercial fisheries. Journal of Fisheries Research Board of Canada 36:859-866. http://dx.doi. org/10.1139/f79-124

Montgomery, W. D. 1972. Markets in licenses and efficient pollution control programs. Journal of Economic Theory 5 (3):395-418. http://dx.doi.org/10.1016/0022-0531(72)90049-X

Newell, R. G., J. N. Sanchirico, and S. Kerr. 2005. Fishing quota markets. Journal of Environmental Economics and Management 49(3):437-462. http://dx.doi.org/10.1016/j.jeem.2004.06.005

Pinkerton, E., and D. N. Edwards. 2009. The elephant in the room: the hidden costs of leasing individual transferable fishing quotas. Marine Policy 33(4):707-713. http://dx.doi.org/10.1016/j. marpol.2009.02.004

Queensland Government, Department of Agriculture, Fisheries and Forestry. 1994-2014. Fisheries act 1994 current to July 2014. Queensland Government, Department of Agriculture, Fisheries and Forestry, Brisbane, Queensland, Australia.

Queensland Government, Department of Agriculture, Fisheries and Forestry. 2008-2014. Fisheries regulation 2008 current to 1 July 2014. Queensland Government, Department of Agriculture, Fisheries and Forestry, Brisbane, Queensland, Australia.

Ramirez-Sanchez, S., and E. Pinkerton. 2009. The impact of resource scarcity on bonding and bridging social capital: the case of fishers' information-sharing networks in Loreto, BCS, Mexico. Ecology and Society 14(1): 22. [online] URL: http://www. ecologyandsociety.org/vol14/iss1/art22/

Scott, J. 1991. Social network analysis: a handbook. Saga, London, UK.

Squires, D., J. Kirkley, and C. A. Tisdell. 1995. Individual transferable quotas as a fisheries management tool. Reviews in Fisheries Science 3(2):141-169. http://dx.doi.org/10.1080/106412$\underline{69509388570}$

Stavins, R. N. 1995. Transaction costs and tradeable permits. Journal of Environmental Economics and Management 29 (2):133-148. http://dx.doi.org/10.1006/jeem.1995.1036

Strogatz, S. H. 2001. Exploring complex networks. Nature 410 (6825):268-276. http://dx.doi.org/10.1038/35065725

Thébaud, O., J. Innes, and N. Ellis. 2012. From anecdotes to scientific evidence? A review of recent literature on catch share systems in marine fisheries. Frontiers in Ecology and the Environment 10(8):433-437. http://dx.doi.org/10.1890/110238

Thébaud, O., J. Innes, A. Norman-López, S. Slade, D. Cameron, T. Cannard, S. Tickell, J. Kung, B. Kerrigan, L. Williams, and L. R. Little. 2014. Micro-economic drivers of profitability in an ITQ- 
managed fishery: an analysis of the Queensland coral reef finfish fishery. Marine Policy 43:200-207. http://dx.doi.org/10.1016/ j.marpol.2013.06.001

van Putten, I., and C. Gardner. 2010. Lease quota fishing in a changing rock lobster industry. Marine Policy 34(5):859-867. http://dx.doi.org/10.1016/j.marpol.2010.01.008

van Putten, I., K. G. Hamon, and C. Gardner. 2011. Network analysis of a rock lobster quota lease market. Fisheries Research 107(1-3):122-130. http://dx.doi.org/10.1016/j.fishres.2010.10.015

Wasserman, S., and K. Faust. 1994. Social network analysis: methods and applications: structure analysis in the social sciences. Cambridge University Press, Cambridge, UK. http://dx.doi. org/10.1017/CBO9780511815478

Weisbuch, G., A. Kirman, and D. Herreiner. 2000. Market organisation and trading relationships. Economic Journal 110 (463):411-436. http://dx.doi.org/10.1111/1468-0297.00531

Wossink, A,. and C. Gardebroek. 2006. Environmental policy uncertainty and marketable permit systems: the Dutch phosphate quota program. American Journal of Agricultural Economics 88:16-27. http://dx.doi.org/10.1111/j.1467-8276.2006.00836.x 


\section{Appendix 1.}

\section{The CRFFF TAC}

As legislated, the commercial RQ TACs should not exceed $1350 \mathrm{t}$ for CT, $700 \mathrm{t}$ for RTE, and $1011 \mathrm{t}$ for OS, however following an allocation appeals process the CT TAC was adjusted to 1423t. The Australian Government Department of Sustainability, Environment, Water, Population and Communities (SEWPaC) subsequently bought out 135t of CT, 73t of RTE and $109 \mathrm{t}$ of $\mathrm{OS}$, in 2004-05, consequently reducing the quantity of quota available to commercial fishers.

\section{Network analysis statistics}

The network analysis statistics were derived as follows. The number of other nodes any single node is directly connected with is its degree $d$. A network is said to be scale-free when its degree distribution, conforms to that of a power distribution (Barabási and Albert 1999).

$$
P(d)=c d^{-\gamma}
$$

where $P(d)$ is the probability $P$ that a node has degree $d, c$ is a normalizing constant, and $\gamma$ is an unknown parameter. For $\gamma<3$ the average degree distribution is considered not representative and the network is deemed to be scale-free (Barabási 2009). Under a power distribution the frequency of very high and very low degree distribution nodes is higher than would be expected had the network formed purely at random (Jackson 2011) and indicates the prominence of high degree nodes acting as hubs.

Several additional statistical measures are also used to assess the networks and are computed using the NetworkAnalyser component of Cytoscape (Assenov et al. 2008). The clustering coefficient is a measure of local cohesiveness and for directed networks

$$
C_{i}=e_{i} /\left(d_{i}\left(d_{i^{-}} 1\right)\right)
$$

where $d_{i}$ is the number of neighbors of $i$ and $e_{i}$ is the number of connected pairs between all neighbors of $i$ and $0<C_{i}<1$. The average clustering coefficient gives an overall indication of the level of clustering in the network as a whole and it has been shown that real world social networks can display high levels of clustering when compared to purely random networks (Watts and Strogatz 1998).

The network diameter indicates the maximum length of shortest paths between two nodes, in terms of the number of edges $d$ between them. The characteristic path length of a network is the average shortest path length between nodes in the network, the shortest path length being $L(i, j)$, where $i$ and $j$ are two separate nodes. A high characteristic path length relative to the number of nodes in the network implies the network is becoming similar to a linear chain whereas a relatively low characteristic path length indicates the network is compact. Characteristics of the nodes themselves are assessed using measures of closeness centrality and betweenness centrality. The closeness centrality of a node can be interpreted as a measure of how fast information may spread between connected nodes in the network (Newman 2003) and is calculated in Cytoscape as the reciprocal of its average shortest path length.

$$
C c(i)=1 / \operatorname{avg}(L(i, j))
$$


where $L(i, j)$ is the length of the shortest path between two nodes $i$ and $j$, and $0<C c<1$ and zero indicates the node is isolated. A high score indicates relatively short paths to other nodes in the network. The betweenness centrality of a node provides an indication of the amount of control exerted by this individual node on interactions in the network, Cytoscape uses the Brandes (2001) algorithm to calculate this:

$$
C b(i)=\sum j \neq I \neq k(\sigma j k(i) / \sigma j k),
$$

where $j$ and $k$ are different nodes to $i, \sigma j k$ is the number of shortest paths from $j$ to $k$, and $\sigma j k(i)$ the number of shortest paths from $j$ to $k$ that $i$ lies on (Brandes 2001).

In the context of trade networks, properties such as those described in this section bear direct relation with the ability of information to spread between groups, and have implications for overall market efficiency.

Table A1.1. Summary characteristics of the coral trout (CT) quota market.

\begin{tabular}{|c|c|c|c|c|c|c|c|c|}
\hline \multicolumn{9}{|c|}{ Coral Trout } \\
\hline & 2004-05 & 2005-06 & 2006-07 & 2007-08 & 2008-09 & 2009-10 & 2010-11 & 2011-12 \\
\hline Account holders & 374 & 293 & 298 & 313 & 320 & 326 & 316 & 325 \\
\hline $\begin{array}{l}\text { Accounts landing fish } \\
\text { Number of lease }\end{array}$ & 165 & 157 & 165 & 172 & 167 & 184 & 173 & 164 \\
\hline trades & 285 & 466 & 356 & 485 & 730 & 539 & 554 & 455 \\
\hline $\begin{array}{l}\text { Lease Trades (LT) (000 } \\
\text { units) }\end{array}$ & 515.27 & 872.72 & 815.64 & 958.48 & 1241.837 & 1157.557 & 750.21 & 615.48 \\
\hline $\begin{array}{l}\text { Lease trades as } \% \\
\text { TAC }\end{array}$ & 0.40 & 0.68 & 0.63 & 0.74 & 0.96 & 0.90 & 0.58 & 0.48 \\
\hline $\begin{array}{l}\text { Permanent Trades } \\
\text { (PT) (000 units) }\end{array}$ & 369.68 & 155.77 & 145.61 & 48.02 & 70.08 & 75.31 & 91.61 & 94.88 \\
\hline $\begin{array}{l}\text { Perm trades as } \% \text { TAC } \\
\% \text { account holders }\end{array}$ & 0.29 & 0.12 & 0.11 & 0.04 & 0.05 & 0.06 & 0.07 & 0.07 \\
\hline lease trading & 0.42 & 0.61 & 0.64 & 0.68 & 0.80 & 0.65 & 0.61 & 0.59 \\
\hline Gini coefficient & 0.66 & 0.70 & 0.75 & 0.77 & 0.77 & 0.78 & 0.78 & 0.78 \\
\hline
\end{tabular}

Table A1.2. Power law values for CT lease trade degree distributions.

\begin{tabular}{rrrrr}
\hline & Coefficient & $2004-2005$ & $2008-2009$ & $2011-2012$ \\
\hline \multirow{2}{*}{ In-degree } & $a$ & 43.572 & 41.46 & 67.825 \\
& $\gamma$ & -1.747 & -1.207 & -1.848 \\
& correlation & 0.979 & 0.994 & 0.994 \\
\multirow{5}{*}{ Out-degree } & $R^{2}$ & 0.937 & 0.852 & 0.878 \\
& $a$ & 65.989 & 44.93 & 54.295 \\
& $\gamma$ & -2.224 & -1.346 & -1.623 \\
& correlation & 0.999 & 0.973 & 0.992 \\
& $R^{2}$ & 0.932 & 0.772 & 0.920 \\
\hline
\end{tabular}

The change in the nature of the networks can also be clearly seen from the $\gamma$ coefficients set out in Table A1.2, which are lowest in the high trade year indicating that hub-type broker nodes played a greater role in that period (also visible in Fig. 4 in the main text). When $\gamma<3$ the average degree distribution is considered to not be representative (Barabási 2009) as the frequency of very high and very low degree distribution nodes is higher than if the network formed randomly (Jackson 2011) and indicates the prominence of highly connected broker (hub-type) nodes in this system. 


\section{Gap analysis}

A modified version of gap analysis outlined in Connor and Alden (2001) was undertaken. This approach accounts for the investor component not consuming quota in the traditional sense of landing fish against it.

$$
\begin{aligned}
& G_{i j(\text { non-investor })}=\frac{L_{i j}}{\left(Q_{i j}+B_{i j}-S_{i j}+I_{i j}-O_{i j}\right)} \\
& G_{i j \text { (investor) }}=\frac{O_{i j}}{\left(Q_{i j}+B_{i j}-S_{i j}+I_{i j}\right)}
\end{aligned}
$$

where $L$ are the landings recorded against quota in year $i$ by account holder $j, Q$ is quota owned at the beginning of year $i, B$ is any quota bought, $S$ is quota sold, $I$ is quota leased in and $O$ is quota leased out. In this way quota held refers to not only the quota they own at the start of the year but also that which may have been bought/sold or leased in/out over the year. As investors do not by definition record catches against the quota they hold, and as such do not 'use' their quota in the same way as other groups, their quota use is defined as the quantity of quota they lease out.

Fig. A1.1. a) evolution of average gap (Gap) and gap weighted by proportion of TAC held (WGap) over time, b) total unused quota at the fishery level in absolute values (tons).
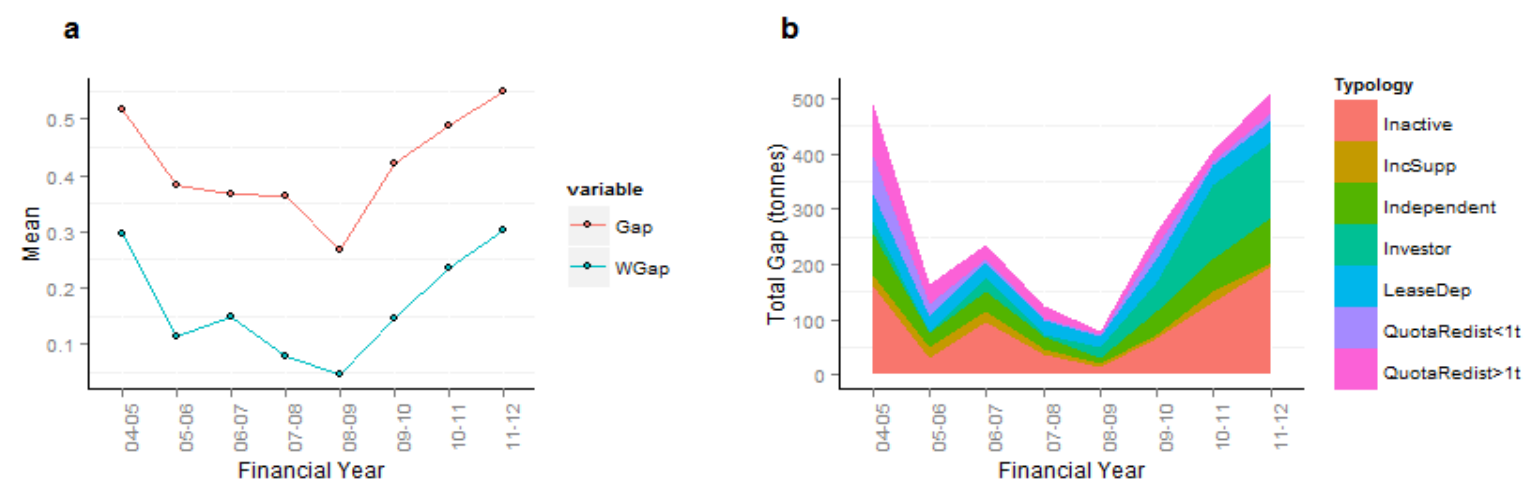

\section{LITERATURE CITED}

Assenov, Y., F. Ramírez, S.-E. Schelhorn, T. Lengauer, and M. Albrecht. 2008. Computing topological parameters of biological networks. Bioinformatics 24(2):282-284.

http://bioinformatics.oxfordjournals.org/content/24/2/282.abstract.

Barabási, A.-L. 2009. Scale-free networks: A decade and beyond. Science 325(5939):412-413.

http://www.sciencemag.org/content/325/5939/412.abstract.

Barabási, A.-L., and R. Albert. 1999. Emergence of scaling in random networks. Science 286(5439):509-512. http://www.sciencemag.org/content/286/5439/509.abstract.

Connor, R., and D. Alden. 2001. Indicators of the effectiveness of quota markets: The south east trawl fishery of australia. Marine and Freshwater Research 52(4):387-397.

Jackson, M. O. 2011. An overview of social networks and economic applications. in: Benhabib J., A. Bisin, M.O. Jackson. editors. The handbook of social economics Elsevier Press.

Watts D. J, Strogatz S. H. 1998. Collective dynamics of 'small-world' networks. Nature. 393:440-2 